\title{
Using Remote Hardware Education Kit to Study Electronics Courses
}

\author{
Sergii V. Afanasiev \\ ORCID 0000-0002-7195-4499 \\ Department of Computer Engineering \\ Chernihiv National University of \\ Technology \\ Chernihiv, Ukraine \\ qvinnn666@gmail.com
}

\author{
Nikita S. Poberezkyi \\ ORCID 0000-0002-5890-2504 \\ Department of Computer Engineering \\ Chernihiv National University of \\ Technology \\ Chernihiv, Ukraine \\ Poberezsky@gmail.com
}

\author{
Sergey A. Ivanets \\ ORCID 0000-0002-9587-0783 \\ Department of Biomedical Radio-Electronic \\ Devices and Systems \\ Chernihiv National University of Technology \\ Chernihiv, Ukraine \\ Sergey.Ivanets@gmail.com
}

\begin{abstract}
Using of remote tools for studying courses in electronics (digital design or microcontroller programming) can increase the efficiency of student learning. RHE (Remote Hardware Education) is a set of software and hardware equipment. And also, to reduce the load on the use of hardware testing, which will entail a reduction in costs for the purchase of components.
\end{abstract}

Keywords-programming, C++, FPGA, master-server, slaveserver.

\section{INTRODUCTION}

The COVID-19 pandemic has forced universities to move to distance education and completely change the way they teach. This has not only led to the intensive use of online technologies for lecturing, but also raised the question of conducting laboratory seminars using real equipment. Learning of digital design is impossible without gaining practical skills. For more, most educational institutions around the world use FPGA. That is reason why students are given the opportunity to study certain disciplines, while testing the acquired skills on the "development boards". With help of these "boards" the student can see immediately whether he understood the theoretical material correctly or not. But, unfortunately, the price on these boards is in such a price range that educational institutions cannot purchase so many units, that each student can work separately. In this case, students must form groups of three or five people and perform laboratory work in teams. It is the lack of individual student work that negatively affects the educational of the course.

To solve this problem, systems are used that allow students to perform laboratory work with hardware remotely, for example, at home, individually, while interacting with the required number of peripherals of the "stand", and see the results through the client $[1,5,9]$.

\section{TECHNICAL CHARACTERISTICS}

RHE (Remote Hardware Education) is a set of software and hardware that allows you to remotely program FPGAs or microcontrollers.

The complex consist of a client part, in the form of a program that connects to the server part via the Internet. In turn, the server part consists of a Master-server, which manages the Slave-servers via wireless communication technologies. Each Slave-server is connecting to a development board with FPGA or microcontroller, which controls the peripherals that are installed on the board. Both Master and Slave servers are Raspberry Pi (specialized single-board computers) [4].

FPGA-based project development will take place on the client side with Quartus Prime software [3]. During development, the student must assign a chip and pins according to the documentation to the development board. While developing a project, the student simulate a project. Student make testbenches in the hardware description language (Verilog or VHDL) and time diagrams are drawn by simulation software [2,8]. These timing diagrams can then be compared with those obtained on the debug board.The development board with the FPGA chip is connected to the slave server. If the project was compiled successfully, the student must upload the FPGA configuration file to the client part of the remote software and send it to the Master-server. This file will be transferred from the main server to the slave server. The FPGA programming tool will be installed on the slave server. In our case, this is Altera Remote JTAG Server - part of the Quartus tools. Slave-servers will program the connected development board through GPIO ports.

In the client part of the remote software, we can also control the signals that are fed to the input ports of the development board and can see signals from the development board.

\section{THE CLIENT PART}

As described above, the client part is a program on the user's computer [6]. The program will have the following interface: login/registration window and the main window. In login/registration window has placed fields for entering login and password; as well as additional fields, for entering last name, first name and organization, which use for registration in the system. The main window will display:

- development board with active components, particularly with switches or keys;

- static output signals from development board that emulate LEDs on board; 
- imitation of logic analyzer, which will show time diagrams from the data lines which the logic analyzer is connected;

- current consumption, which is read from the ammeter and allows experiments to measure the dependence of current on the frequency and size of the project on the FPGA;

- field for downloading the firmware file to the debugging board.

In case of working with the debugging board with FPGA, the client part will analyze the firmware file, in order to check the correct connection of such baselines as 'clk', 'reset' and switch lines according to the specific board.

\section{THE SERVER}

The server is required to receive a request from a user who sends this request from the client side [7]. The server is essentially divided into two major sub-parts: part of the main control (Master-server) and part of the child controls (Slaveserver). The main control element is the part that is responsible for receiving the request from the user, then analyzes among a number of child elements and selects the one, that can process this request in the future. After the child element has been selected, the Master-server generates request to the Slave-server: this request includes commands, that directly control the process of interaction with the FPGA. When the FPGA-board starts, the Slave-server will analyze the activity on the I/O ports, generate and send data packets to the Master-server; the main control will forward the packets to the client.

Every Slave-server, that interacts with the FPGA, is allocated for each active session. The Master-server in turn acts as an arbiter.

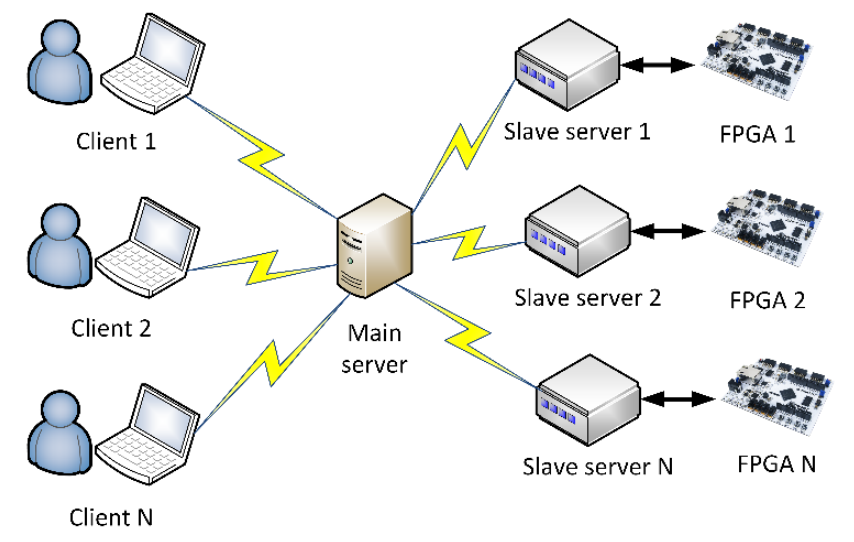

Fig. 1. Block diagram of the complex RHE

\section{PART OF THE MAIN CONTROL ELEMENT}

Both a regular computer and a specialized computer can be selected as the main control element (Master-server). The main requirement for the executing of this component is the operating system, which provides reception and processing of requests from the client, analysis of these requests and transmission to the selected child control (Slave-server) and the implementation of reverse exchange. Also, the task of the Master-server is to manage the process of working with many clients at the same time - this allows many students to perform work contemporaneously.

\section{PART OF THE CHILD CONTROLS}

It is planned to choose a specialized computer with a high-level operating system for the role of one control element (Slave-server). This allows the use of multi-level software modules, services and drivers, which speeds up system development and simplifies software support in the future. For example, instead of creating an interface for FPGA programming, you can install a special driver for the programmer chip. One of the tasks of the Slave-server is the analysis of logical levels on the I/O ports: after starting the FPGA firmware, all logical levels will be read, data packets will be formed and sent to the Master-server; the Masterserver will send packets to the client, and the client will simulate and display the result in the form of time diagram.

The developed system provides several such controls. Each FPGA-board must have its own control (Slave-server), which will be subordinated to the main control (Masterserver).

An ammeter is used to measure the current consumption of the development board, which can be connected to a Slave-server via a USB port. This simple methods allows you to see how the current changes depending on the system frequency, the size of the project on the FPGA chip.

\section{CONCLUSIONS}

The complex described in this article will allow you to work remotely with FPGA or microcontroller development board. This opportunity provides a solid foundation for building in the field of hardware, the process of distance learning, which is becoming increasingly popular every day, or is the only means of learning during today's emergencies. Also, remote work with hardware has great potential in creating an Internet service that provides a hardware platform for users, who do not have the opportunity to purchase a similar platform.

\section{REFERENCES}

[1] F. Morgan et al., "Remote FPGA Lab with Interactive Control and Visualisation Interface," 2011 21st International Conference on Field Programmable Logic and Applications, Chania, 2011, pp. 496-499, doi: 10.1109/FPL.2011.98.

[2] Proektuvannya komp'yuternykh system na osnovi mikroskhem prohramovanoyi lohiky: monohrafiya / avt: V. V. Kazymyr, V. V. Lytvynov, S. A. Ivanets'. - Chernihiv: Chernihivs'kyy natsional'nyy tekhnolohichnyy universytet, 2013. - $305 \mathrm{~s}$.

[3] Quartus ${ }^{\circledR}$ Prime Standard Edition Handbook. Intel Corp., 2017.

[4] Raspberry Pi (Trading) Ltd, "Raspberry Pi Compute Module 3+ Datasheet, " Raspberry Pi (Trading) Ltd, 2019, pp. 7-8.

[5] A. I. Strelets, V. S. Ivannikov, M. N. Yokhin and A. A. Skitev, "FPGA-based configurable virtual stand," 2018 IEEE Conference of Russian Young Researchers in Electrical and Electronic Engineering (EIConRus), Moscow, 2018, pp. 374-378, doi: 10.1109/EIConRus.2018.8317110.

[6] B. Stroustrup, "Programming Principles and Practice Using C++," Moscow: Williams, 2016, pp. 456-467.

[7] E. Tanenbaum, D. Weatheroll, "Computer networks, " 5th ed., St. Petersburg: Piter, 2012, pp. 770-778.

[8] Tsifrovoy sintez: prakticheskiy kurs / pod obshch. red. A. Y. Romanova, Y. V. Panchula. - M.: DMK Press, 2020. - 556 s.

[9] M. Winzker and A. Schwandt, "Open Education Teaching Unit for Low-Power Design and FPGA Image Processing," 2019 IEEE Frontiers in Education Conference (FIE), Covington, KY, USA, 2019, pp. 1-9, doi: 10.1109/FIE43999.2019.9028694. 